\title{
Laporan kasus berbasis bukti Peran Metode Noninvasif dalam Mendeteksi Varises Esofagus Signifikan pada Anak dengan Hipertensi Portal
}

\author{
William Jayadi Iskandar, Hanifah Oswari \\ Departemen Ilmu Kesehatan Anak Fakultas Kedokteran Universitas Indonesia Rumah Sakit dr. Cipto Mangunkusumo, Jakarta
}

Latar belakang. Esofagogastroduodenoskopi (EGD) penting dilakukan pada anak dengan hipertensi portal untuk mendeteksi varises esofagus signifikan (derajat II, III, atau stigmata perdarahan), tetapi prosedur ini invasif dan traumatik.

Tujuan. Mengetahui kemampuan metode noninvasif dibandingkan EGD dalam menentukan varises esofagus signifikan pada anak dengan hipertensi portal.

Metode. Penelusuran literatur melalui Pubmed, Scopus, dan Cochrane Library dilakukan pada tanggal 25 Juni 2019. Kriteria inklusi adalah subyek anak hingga berusia 18 tahun, dipublikasi dalam 5 tahun terakhir, berbahasa Inggris, dan tersedia full text. Kriteria eksklusi adalah subyek pascaoperasi atau tidak membahas metode noninvasif. Artikel terpilih kemudian dinilai secara kritis.

Hasil. Tiga buah artikel penelitian ditemukan, terdiri atas sebuah telaah sistematik dan dua buah penelitian observasional. Metode noninvasif yang memiliki sensitivitas tinggi adalah clinical prediction rule (80\%), varices prediction rule (80\%), dan risk score (85,7\%). Metode yang memiliki spesifisitas tinggi adalah King's variceal prediction score (72,7\%).

Kesimpulan. Metode noninvasif dapat digunakan untuk memilih prioritas pasien anak dengan hipertensi portal yang perlu dilakukan EGD untuk menentukan varises esofagus signifikan. Sari Pediatri 2020;22(3):182-9

Kata kunci: hipertensi portal, varises esofagus, endoskopi

\section{Evidence base case report The Role of Noninvasive Methods on Diagnosing Clinically Significant Esophageal Varices in Children with Portal Hypertension}

William Jayadi Iskandar, Hanifah Oswari

Background. Esophagogastroduodenoscopy (EGD) would diagnose clinically significant esophageal varices (grade II, III, or red wale markings/cherry red spots) in children with portal hypertension, but the procedure is invasive and traumatic.

Objective. To investigate the role of noninvasive methods, compared to EGD, on diagnosing clinically significant esophageal varices in children with portal hypertension.

Methods. Literature searching through Pubmed, Scopus, and Cochrane Library was conducted on June 25 ${ }^{\text {th }} 2019$. Inclusion criteria was human subjects, age $<18$ years, published in the last 5 years, English, and full text available. Perioperative subjects and articles without noninvasive methods were excluded. The useful articles were critically appraised.

Results. Three useful articles were found, consisted of one systematic review and two original articles. Noninvasive methods possessing high sensitivity are clinical prediction rule (80\%), varices prediction rule $(80 \%)$, and risk score $(85,7 \%)$. The only test having high specificity is King's variceal prediction score $(72,7 \%)$.

Conclusion. Noninvasive methods may be used to select children with portal hypertension that should have EGD to confirm clinically significant esophageal varices. Sari Pediatri 2020;22(3):182-9

Keywords: portal hypertension, esophageal varices, endoscopy

Alamat korespondensi: Hanifah Oswari. Departemen Ilmu Kesehatan Anak Fakultas Kedokteran Universitas Indonesia, RSUPN dr. Cipto Mangunkusumo, Jalan Diponegoro No.71, Jakarta Pusat, 10430. Email: hoswari@gmail.com. 
William Jayadi Iskandar dkk: Peran metode noninvasif dalam mendeteksi varises esofagus signifikan dengan hipertensi portal

$\mathrm{V}$ arises esofagus merupakan komplikasi utama dari hipertensi portal, serta memiliki tingkat morbiditas dan mortalitas yang bervariasi. Sebanyak 70-90\% pasien anak dengan hipertensi portal memiliki varises esofagus, dengan angka kejadian perdarahan saluran cerna akibat pecah varises berkisar 17-42\%. ${ }^{1,2}$ Risiko perdarahan dapat meningkat menjadi $38 \%$ dalam waktu lima tahun setelah varises didiagnosis. ${ }^{3}$ Tujuhpuluh lima persen episode pertama pecah varises esofagus di negara maju terjadi sebelum usia 2,5 tahun dengan risiko mortalitas sebesar $<1 \% .{ }^{4}$ Hal utama penyebab mortalitas rendah akibat pecah varises esofagus, antara lain, akses pelayanan medis, khususnya endoskopi saluran cerna atas, dan upaya profilaksis yang optimal, baik primer sebelum terjadi perdarahan maupun sekunder setelah terjadi perdarahan. Hingga saat ini belum ada panduan profilaksis primer atau sekunder pada varises esofagus anak. Hal tersebut berbeda dengan dewasa yang mewajibkan endoskopi saluran cerna atas pada saat diagnosis sirosis hati ditegakkan. ${ }^{5}$

Endoskopi saluran cerna atas (esofagogastroduodenoskopi, disingkat EGD) merupakan baku emas untuk mendiagnosis varises esofagus dan menentukan derajat berat varises, serta dapat digunakan sekaligus untuk terapi. Klasifikasi derajat varises esofagus saat ini bermacam-macam. Namun, klasifikasi yang dipakai secara umum pada anak adalah derajat nol (tanpa varises), derajat satu (kecil, tidak berkelok, dan mendatar saat dilakukan insufflation), dua (berkelok dan menempati hampir sepertiga radius esofagus distal tapi tidak mendatar saat dilakukan insufflation), dan tiga (besar, berkelok, menempati lebih dari sepertiga radius esofagus distal, dan confluent). ${ }^{1,5}$ Angka kejadian varises esofagus derajat dua dan tiga pada pasien sirosis anak akibat atresia bilier yang terbukti melalui endoskopi dapat mencapai 96\%. 6 Skrining EGD pada pasien anak berusia di bawah dua tahun dengan hipertensi portal menunjukkan varises esofagus derajat dua dan tiga sebanyak $28 \%$, dan $20 \%$ mengalami perdarahan. ${ }^{2}$ Di sisi lain, endoskopi anak merupakan pemeriksaan invasif atau traumatik, berbiaya tinggi, serta membutuhkan keahlian dan dilakukan di fasilitas tersier. Selain itu, pajanan zat anestetik berulang dikaitkan dengan penurunan kecerdasan anak. ${ }^{4} \mathrm{Hal}$ tersebut disertai mortalitas yang rendah akibat pecah varises esofagus di negara maju mendorong pengembangan metode noninvasif sebagai alternatif terhadap EGD untuk menentukan varises esofagus signifikan pada pasien anak dengan penyakit hati kronik atau hipertensi portal.

Selama dekade terakhir, berbagai macam metode noninvasif dikembangkan untuk memprediksi varises esofagus signifikan, antara lain, jumlah trombosit, panjang limpa, rasio trombosit-panjang limpa, clinical prediction rule, dan lain-lain. ${ }^{7-9}$ Metodemetode tersebut digunakan sebagai skrining atau alat bantu untuk memilih prioritas pasien hipertensi portal yang akan menjalani EGD. Tujuan sajian kasus berbasis bukti ini adalah untuk mengetahui kemampuan metode noninvasif dibandingkan EGD dalam menentukan varises esofagus signifikan pada pasien anak dengan hipertensi portal. Varises esofagus signifikan adalah varises yang berisiko tinggi pecah dan berdarah, antara lain varises derajat dua, tiga, atau terdapat stigmata perdarahan, seperti red wale markings atau cherry red spots dan varises gastrik atau gastropati portal. ${ }^{1,2,5}$ Hipertensi portal secara klinis ditegakkan jika ditemukan asites, splenomegali, atau trombositopenia. ${ }^{2}$

\section{Skenario klinis}

Seorang anak lelaki, MZ, berusia 9 bulan, datang kontrol rutin ke poliklinik RSCM. Pasien sebelumnya dirujuk ke RSCM pada usia 4 bulan dengan keluhan utama kuning disertai tinja berwarna dempul yang disadari orangtua sejak usia 1 bulan. Pemeriksaan laboratorium, ultrasonografi, dan biopsi hati sudah dilakukan, ditegakkan diagnosis sirosis hati akibat atresia bilier dan direncanakan transplantasi hati. Hingga sekarang pasien belum pernah mengalami perdarahan saluran cerna, walaupun perut tampak membesar akibat splenomegali dan asites. Data pemeriksaan penunjang terakhir menunjukkan trombosit $278.000 / \mu \mathrm{L}$, albumin $2,2 \mathrm{~g} / \mathrm{dL}$, aspartate transaminase (AST, atau dikenal sebagai SGOT) 86 IU/L (batas atas $70 \mathrm{IU} / \mathrm{L}$ ), dan panjang limpa $11,6 \mathrm{~cm}$ (rerata ukuran pada laki-laki usia 6-12 bulan sebesar $6,4 \mathrm{~cm}$ dan SD 0,78, menghasilkan $z$ score 6,67). Timbul pertanyaan, apakah ia perlu diendoskopi atau adakah metode noninvasif yang dapat digunakan untuk mendeteksi varises esofagus signifikan pada anak tersebut karena profilaksis primer perlu dilakukan untuk mencegah perdarahan. 
William Jayadi Iskandar dkk: Peran metode noninvasif dalam mendeteksi varises esofagus signifikan dengan hipertensi portal

\section{Pertanyaan klinis}

Berdasarkan ilutrasi kasus tersebut, dirumuskan pertanyaan klinis sebagai berikut.

$\mathrm{P}$ (patient) : pasien anak usia kurang dari 18 tahun dengan hipertensi portal

I (intervention) : metode noninvasif

C (comparison) : endoskopi saluran cerna atas (esofagogastroduodenoskopi, EGD)

$\mathrm{O}$ (outcome) : varises esofagus signifikan (clinically significant varices)

\section{Metode penelusuran literatur}

Penelusuran literatur dalam mesin pencari Pubmed, Scopus, dan Cochrane Library dilakukan pada tanggal 25 Juni 2019 dengan menggunakan terminologi sesuai Tabel 1 dan strategi pencarian seperti tertera pada Gambar 1. Kriteria inklusi, antara lain, adalah artikel yang dipublikasi dalam lima tahun terakhir dan berbahasa Inggris, tersedia full text, subyek penelitian manusia, anak hingga berusia delapan belas tahun, dan desain studi adalah observasional, penelitian klinis, telaah sistematik, atau metaanalisis. Kriteria pencarian tersebut diterapkan dalam fungsi filter atau limit bergantung pada mesin pencari.

Setelah membaca judul dan abstrak, artikel yang relevan dipilih dengan mengeksklusi artikel yang tidak membahas metode noninvasif atau subyek pascaoperasi. Artikel tersebut kemudian dinilai secara kritis dengan alat penilaian dari laman Oxford Centre for Evidence-based Medicine (www.cebm.net) untuk jenis atau desain studi yang sesuai. Definisi metode noninvasif, termasuk rumus perhitungan dan nilai cut-off serta hasil perhitungan pada pasien dijelaskan lebih rinci pada Lampiran 1.

\section{Hasil penelusuran literatur}

Strategi pencarian menghasilkan tiga artikel bermanfaat, yakni satu telaah sistematik dan dua artikel penelitian (Gambar 1). Colli $\mathrm{dkk}^{7}$ membuat telaah sistematik yang bertujuan menentukan akurasi diagnostik jumlah trombosit, panjang limpa, atau rasio trombosit-panjang limpa, terhadap EGD sebagai baku emas dalam mendiagnosis varises esofagus pada pasien anak atau dewasa dengan penyakit hati kronik atau trombosis vena porta. Pencarian literatur menggunakan beberapa register penelitian manual dan mesin pencari elektronik tanpa batasan bahasa atau jenis dokumen, kemudian dinilai secara kritis dengan panduan Cochrane untuk studi diagnostik. Sebanyak empat artikel pada anak ditemukan dengan desain potong lintang, dengan jumlah kumulatif sebanyak 277 pasien dan luaran berupa varises (any varices).

Berdasarkan hasil pooled analysis, hitung trombosit dengan nilai cut-off $<115.000 / \mathrm{mm}^{3}$ memiliki sensitivitas 0,71 (IK95\% 0,60 hingga 0,80) dan spesifisitas 0,83 (IK95\% 0,70 hingga 0,91). Rasio trombositpanjang limpa ( $z$ score) dengan nilai cut-off $<25$ memiliki sensitivitas 0,74 (IK95\% 0,65 hingga 0,81) dan spesifisitas 0,64 (IK95\% 0,36 hingga 0,84). Di antara kedua pemeriksaan noninvasif tersebut, rasio trombosit-panjang limpa dapat digunakan untuk memilih pasien yang membutuhkan endoskopi, tetapi tidak cukup akurat dalam mengidentifikasi jenis varises esofagus risiko tinggi yang membutuhkan profilaksis primer, atau dengan kata lain varises klinis signifikan. Hasil penilaian kritis dan forest plot tertera Tabel 2.

Tabel 1. Lokasi penelusuran dan terminologi

\begin{tabular}{|c|c|c|c|}
\hline Lokasi & Terminologi & Hasil & Terpilih \\
\hline Pubmed & $\begin{array}{l}\text { "portal hypertension" AND endoscop* AND varice* } \\
\text { Filter: publikasi dalam lima tahun terakhir; subyek manusia; usia anak hingga } \\
18 \text { tahun; bahasa Inggris; tersedia full text; desain studi observasional, telaah } \\
\text { sistematik, atau metaanalisis }\end{array}$ & 10 & 1 \\
\hline Scopus & $\begin{array}{l}\text { "portal hypertension" AND endoscop* AND varice* } \\
\text { Limit: publikasi dalam lima tahun terakhir; subyek manusia; pediatric OR } \\
\text { paediatric*; bahasa Inggris; tersedia full text; artikel penelitian }\end{array}$ & 92 & 2 \\
\hline $\begin{array}{l}\text { Cochrane } \\
\text { Library }\end{array}$ & $\begin{array}{l}\text { "portal hypertension" AND endoscop* AND varice* } \\
\text { Filter: publikasi dalam lima tahun terakhir, studi diagnostik, bahasa Inggris }\end{array}$ & 2 & 1 \\
\hline
\end{tabular}




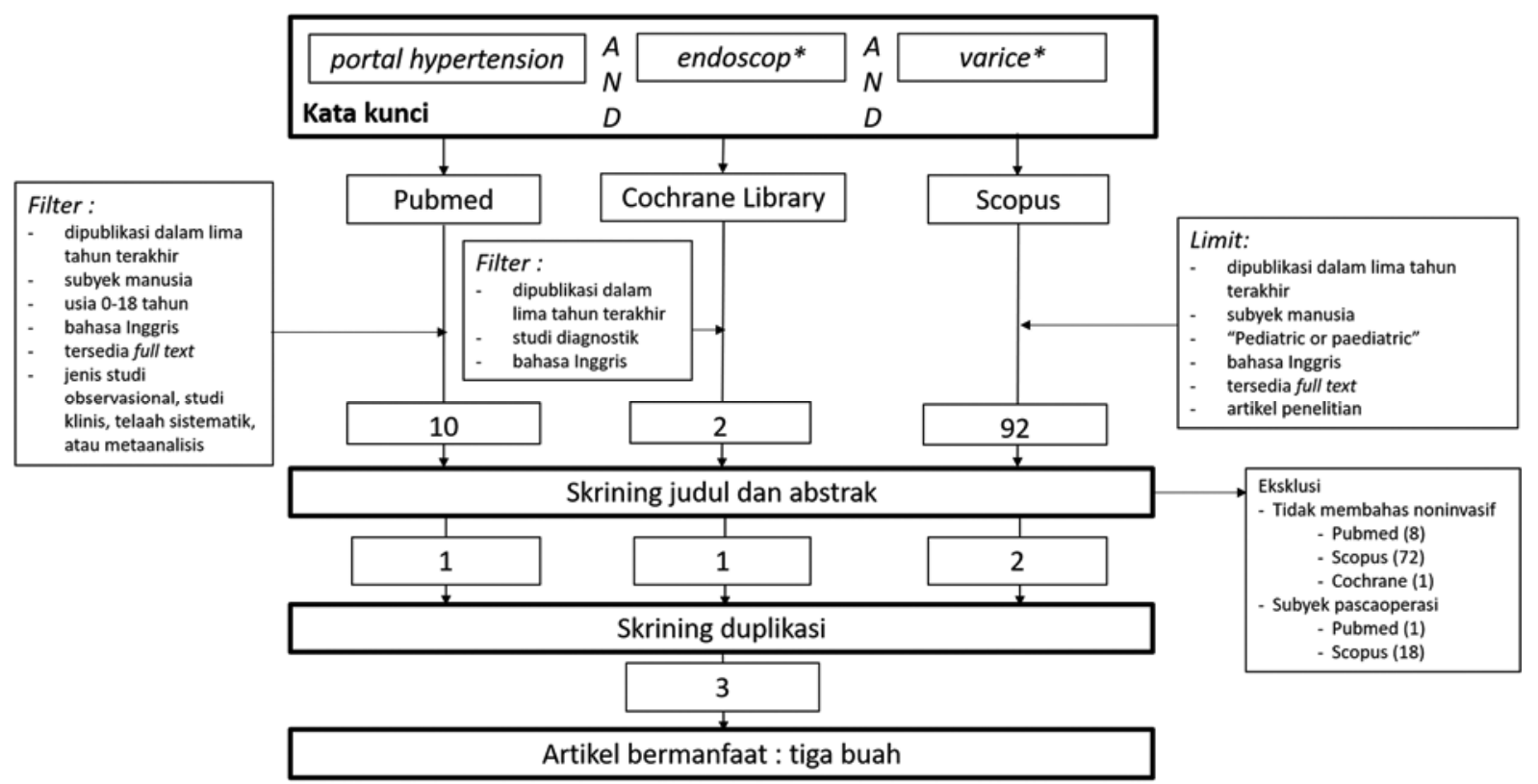

Gambar 1. Alur penelusuran literatur pada tanggal 25 Juni 2019

Tabel 2. Penilaian kritis telaah sistematik

Artikel: Colli $\mathrm{dkk}^{7}$

Level of evidence : 1 (systematic review)

Pertanyaan klinis

- P : anak dan dewasa dengan penyakit hati kronik atau trombosis vena porta tanpa memandang etiologi

- I : metode noninvasif (jumlah trombosit, panjang limpa, atau rasio trombosit-panjang limpa)

- C : esofagogastroduodenoskopi (EGD)

- O : varises esofagus (ada atau tidak ada)

Question

Apakah telaah sistematik menyatakan pertanyaan terarah (PICO) dan menggunakannya untuk mengarahkan pencarian dan memilih artikel?

Find

Apakah kecil kemungkinan ada penelitian penting yang terlewat?

Appraise

Apakah kriteria inklusi penelusuran artikel tepat?

Ya

Apakah penelitian yang ditemukan cukup valid untuk menjawab pertanyaan?

Ya

Result

Apakah hasil antarpenelitian serupa?

Adami $\mathrm{dkk}^{9}$ meneliti peran parameter noninvasif untuk memprediksi varises besar pada anak dengan hipertensi portal intrahepatik. Definisi varises besar adalah varises derajat dua, tiga, atau terdapat perdarahan, sedangkan varises kecil adalah derajat satu atau tanpa varises. Sebanyak 98 anak dari tahun 2000-2011 yang belum pernah mengalami perdarahan saluran cerna dilakukan EGD dan dibandingkan dengan beberapa parameter noninvasif seperti jumlah trombosit, clinical prediction rule (CPR), dan risk score menggunakan data dalam tiga bulan terakhir. Parameter tersebut diuji dalam metode regresi logistik dengan luaran kelompok varises besar dan kelompok varises kecil. Metode noninvasif terbaik adalah jumlah trombosit dibagi $z$ score ukuran limpa $<25$ (AUROC 0,67; IK95\% 0,57 hingga 0,78), diikuti clinical prediction rule $<114$ (AUROC 0,65; IK95\% 0,54 hingga 0,76 ), dan risk score lebih besar dari $-1,2$ 
William Jayadi Iskandar dkk: Peran metode noninvasif dalam mendeteksi varises esofagus signifikan dengan hipertensi portal

Tabel 3. Penilaian kritis studi diagnostik

\begin{tabular}{|c|c|c|c|c|c|c|}
\hline Artikel & & & & & $\begin{array}{l}\text { Adami } \\
\mathrm{dkk}^{9}\end{array}$ & $\begin{array}{l}\text { Witters } \\
\mathrm{dkk}^{10}\end{array}$ \\
\hline \multicolumn{5}{|l|}{ Level of evidence } & 2 & \\
\hline \multicolumn{7}{|l|}{ Validity } \\
\hline \multicolumn{5}{|c|}{ Apakah uji diagnostik dilakukan pada spektrum pasien yang representatif? } & Ya & Ya \\
\hline \multicolumn{5}{|c|}{ Apakah baku emas tetap dilakukan tanpa memandang hasil uji indeks? } & Ya & Ya \\
\hline \multicolumn{5}{|c|}{ Apakah dilakukan pengukuran yang independen atau tersamar antara uji indeks dengan baku emas? } & Ya & Ya \\
\hline \multicolumn{7}{|l|}{ Importance } \\
\hline Alat uji ${ }^{10}$ & $\begin{array}{l}\text { Nilai } \\
\text { cut-off }\end{array}$ & $\begin{array}{c}\text { Spesifisitas } \\
(\%)\end{array}$ & $\begin{array}{c}\text { Sensitivitas } \\
(\%)\end{array}$ & $\begin{array}{l}\text { Nilai duga } \\
\text { positif (\%) }\end{array}$ & \multicolumn{2}{|l|}{$\begin{array}{l}\text { Nilai duga } \\
\text { negatif (\%) }\end{array}$} \\
\hline CPR & 114 & 59,1 & 76,3 & 75,6 & \multicolumn{2}{|l|}{57,6} \\
\hline APRI & 1,603 & 55,6 & 60,3 & 70,1 & \multicolumn{2}{|l|}{44,7} \\
\hline Rasio trombosit-panjang limpa & 447,3 & 56,2 & 76,3 & 74,5 & \multicolumn{2}{|l|}{58,5} \\
\hline VPR & 3,63 & 59 & 80 & 77,2 & \multicolumn{2}{|l|}{63} \\
\hline KVaPS & 76 & 72,7 & 71,8 & 81,6 & \multicolumn{2}{|l|}{60,4} \\
\hline Alat uji & $\begin{array}{l}\text { Nilai } \\
\text { cut-off }\end{array}$ & $\begin{array}{c}\text { Spesifisitas } \\
(\%)\end{array}$ & $\begin{array}{c}\text { Sensitivitas } \\
(\%)\end{array}$ & $\begin{array}{l}\text { Nilai duga } \\
\text { positif (\%) }\end{array}$ & \multicolumn{2}{|l|}{$\begin{array}{l}\text { Nilai duga } \\
\text { negatif (\%) }\end{array}$} \\
\hline Trombosit & $<115.000$ & 54,4 & 65,7 & 75,5 & \multicolumn{2}{|l|}{42,5} \\
\hline APRI & $>1,4$ & 47 & 57,1 & 68 & \multicolumn{2}{|l|}{35,7} \\
\hline Rasio trombosit-limpa (atas $z$ & $<25$ & 54,7 & 71,4 & 74,3 & \multicolumn{2}{|l|}{51} \\
\hline score, bawah cm) & $<1$ & 44,4 & 71,4 & 70,6 & \multicolumn{2}{|l|}{45,4} \\
\hline Risk score & $>-1,2$ & 46,3 & 85,7 & 86,1 & \multicolumn{2}{|l|}{45,4} \\
\hline $\mathrm{CPR}$ & $<115$ & 47,2 & 80 & 78,1 & \multicolumn{2}{|l|}{50} \\
\hline $\mathrm{CPR}$ & $<114$ & 52,8 & 80 & 80 & \multicolumn{2}{|l|}{52,8} \\
\hline \multicolumn{7}{|l|}{ Applicability } \\
\hline \multicolumn{5}{|c|}{ Apakah metode pemeriksaan indeks dapat dilakukan? } & Ya & Ya \\
\hline
\end{tabular}

$\mathrm{CPR}=$ clinical prediction rule, $\mathrm{APRI}=$ AST/platelet ratio index, $\mathrm{VPR}=$ variceal prediction rule, $\mathrm{KVaPS}=$ King's variceal prediction score

(AUROC 0,66; IK95\% 0,56 hingga 0,76).

Witters $\mathrm{dkk}^{10}$ meneliti data klinis 124 pasien anak dengan kecurigaan hipertensi portal atau perdarahan saluran cerna yang menjalani prosedur EGD selama tahun 2005 hingga 2012 dengan luaran varises klinis signifikan (derajat dua, tiga, atau stigmata perdarahan). Data klinis dan penunjang pasien dikumpulkan dalam enam bulan terakhir. Sebanyak $50 \%$ subyek mengalami atresia bilier, $28 \%$ subyek perdarahan saluran cerna, dan $64 \%$ subyek memiliki varises signifikan. Sensitivitas dan spesifisitas untuk clinical prediction rule (CPR), indeks rasio SGOT-trombosit (APRI), dan varices prediction rule (VPR) masing-masing 76\% dan 59\%, 60\% dan 55\%, serta 80\% dan 59\%. Mereka merumuskan skor baru yang disebut King's variceal prediction score yang telah divalidasi pada sampel lain dengan sensitivitas dan spesifisitas sebesar 71,8\% dan
72,7\%. Skor tersebut dapat dipakai untuk menentukan prioritas pasien yang perlu dilakukan EGD untuk mencegah perdarahan akibat pecah varises esofagus. Hasil penilaian kritis kedua artikel tersebut tertera pada Tabel 3.

\section{Pembahasan}

Pengembangan metode noninvasif untuk menentukan varises esofagus signifikan pada anak tidak sebanyak studi pada dewasa karena beberapa hal berikut. Pertama, rentang nilai normal pada dewasa hampir seragam, berbeda dengan anak..$^{1,4,6}$ Salah satu upaya untuk menyeragamkan nilai normal tersebut antara lain dengan pengembangan rumus estimasi panjang limpa dewasa atau dengan $z$ score. ${ }^{10}$ Kedua, penyebab 
penyakit hati kronik atau hipertensi portal pada anak sangat bervariasi, mulai dari penyakit kongenital hingga penyakit infeksi, sedangkan penyebab penyakit hati kronik pada dewasa relatif seragam akibat infeksi (virus hepatitis) atau alkohol. Ketiga, anak termasuk dalam subyek populasi rentan (vulnerable subjects) sehingga jumlah studi klinis pada anak lebih sedikit daripada dewasa.

Ketiga artikel bermanfaat tersebut memiliki perbedaan dalam definisi varises esofagus sebagai luaran. Telaah sistematik oleh Colli $\mathrm{dkk}^{7}$ tidak merinci jenis atau derajat varises esofagus, tetapi sebatas ada atau tidak (any varices). Dua artikel lainnya menggunakan istilah varises klinis signifikan, yakni derajat dua, tiga, atau stigmata perdarahan. Oleh karena itu, kedua artikel terakhir merupakan artikel yang lebih relevan dalam menjawab pertanyaan klinis terkait varises klinis signifikan, walaupun level of evidence telaah sistematik lebih tinggi.

Hasil penilaian kritis pada ketiga artikel bermanfaat menunjukkan metode penelitian yang cukup valid, hasil yang penting, dan dapat diterapkan pada populasi pasien anak di Indonesia. Pemeriksaan laboratorium seperti trombosit dan SGOT, serta pengukuran panjang limpa dengan ultrasonografi dapat dilakukan di fasilitas kesehatan. Walau demikian, hingga saat ini belum ada normogram ukuran limpa pada anak Indonesia, untuk mendapatkan nilai $z$ score yang digunakan dalam beberapa metode noninvasif. Normogram yang dipakai saat ini bersumber dari hasil pengukuran populasi anak sehat di Yunani pada tahun 2004. ${ }^{11}$ Nilai $z$ score dan SD yang diperoleh selanjutnya dapat diekstrapolasikan menjadi estimasi ukuran limpa pada dewasa dengan rumus tertentu (Lampiran 1). ${ }^{10}$

Dalam studi diagnostik, sensitivitas dan spesifisitas berperan penting dalam menentukan kesahihan suatu alat uji baru dibandingkan baku emas dan tidak bergantung pada prevalens atau angka kejadian penyakit. Spesifisitas yang tinggi berperan untuk menegakkan suatu diagnosis jika hasil positif (rule in), sedangkan sensitivitas yang tinggi bermanfaat untuk menyingkirkan suatu penyakit jika hasil negatif (rule $o u t$ ). Berdasarkan artikel tersebut, metode yang memiliki sensitivitas tinggi sekitar $80 \%$ adalah risk score, clinical prediction rule (CPR) dan varices prediction rule (VPR), sedangkan metode yang memiliki spesifisitas tinggi sebesar $76 \%$ adalah King's variceal prediction score (KVaPS). Dengan kata lain, metode KVaPS, risk score, CPR, dan VPR dapat digunakan untuk membantu prioritas pasien yang perlu dilakukan EGD guna menilai varises esofagus signifikan. Di sisi lain, metode APRI, hitung trombosit, dan rasio trombosit-panjang limpa memiliki spesifisitas dan sensitivitas yang lebih rendah dibandingkan metode lainnya. Hingga sekarang belum ada studi serupa pada anak di Indonesia.

Berdasarkan temuan tersebut, sebuah panduan untuk menentukan prioritas pasien yang perlu dilakukan EGD sebagai profilaksis primer diusulkan sebagai berikut. Pertama, pasien dengan penyakit hati kronik dan manifestasi klinis hipertensi portal (asites atau splenomegali), dianjurkan menjalani pemeriksaan darah tepi lengkap (khususnya trombosit), albumin, AST (SGOT), dan ultrasonografi abdomen untuk menghitung panjang limpa. Selanjutnya, probabilitas varises esofagus signifikan dihitung dengan metode KVaPS, risk score, CPR, atau VPR. Jika USG tidak tersedia, metode risk score atau VPR dapat digunakan. Pasien yang memiliki skor melewati nilai cut-off diprioritaskan untuk menjalani prosedur EGD untuk menilai varises esofagus signifikan.

Pada pasien skenario klinis, telah dilakukan perhitungan dengan berbagai metode noninvasif (Lampiran 1), dan pasien memiliki probabilitas tinggi mengalami varises esofagus signifikan. Dengan kata lain, pasien perlu diendoskopi untuk mendiagnosis pasti varises esofagus signifikan.

\section{Kesimpulan}

Metode noninvasif dapat digunakan untuk memilih prioritas pasien anak dengan manifestasi klinis hipertensi portal yang perlu dilakukan endoskopi saluran cerna atas untuk menentukan varises esofagus signifikan. Metode noninvasif dapat dilakukan dengan metode clinical prediction rule, varices prediction rule, atau risk score yang memiliki sensitivitas tinggi, atau King's variceal prediction score (KVaPS) yang memiliki spesifisitas tinggi.

\section{Daftar pustaka}

1. Bozic MA, Puri K, Molleston JP. Screening and prophylaxis for varices in children with liver disease. Curr Gastroenterol Rep 2015;17:27-34.

2. Chapin CA, Bass LM. Cirrhosis and portal hypertension in the pediatric population. Clin Liver Dis 2018;22:735-52. 
3. Feldman AG, Suchy FJ. Portal hypertension and varices. Dalam: Kliegman RM, Geme JS, penyunting. Nelson textbook of pediatrics. Edisi ke-21. Philadelphia: Elsevier Inc; 2019. h.2141-3.

4. Shneider BL, Goyet JV, Leung DH, Srivastava A, Ling SC, Duche $\mathrm{M}$, dkk. Primary prophylaxis of variceal bleeding in children and the role of MesoRex Bypass: Summary of the Baveno VI pediatric satellite symposium. Hepatology 2016;63:1368-80.

5. Grammatikopoulos T, Mckiernan PJ, Dhawan A. Portal hypertension and its management in children. Arch Dis Child 2017;31:1-6.

6. Duché M, Ducot B, Ackermann O, Guérin F, Bernard O. Portal hypertension in children: High-risk varices, primary prophylaxis and consequences of bleeding. J Hepatol 2017;66:320-7.

7. Colli A, Ganam JC, Yap J, Adams-Webber T, Rashkovan N, Ling SC, dkk. Platelet count, spleen length, and platelet countto-spleen length ratio for the diagnosis of oesophageal varices in people with chronic liver disease or portal vein thrombosis. Cochrane Database Syst Rev2017;4:1-212.

8. Sutton H, Dhawan A, Grammatikopoulos T. Non-invasive markers of portal hypertension: appraisal of adult experience and potential utilisation in children. J Pediatr Gastroenterol Nutr 2018;66:559-69.

9. Adami MR, Kieling CO, Schwengber FP, Hirakata VN, Vieira SMG. Noninvasive methods of predicting large esophageal varices in children with intrahepatic portal hypertension. J Pediatr Gastroenterol Nutr 2018;66:442-6.

10. Witters P, Hughes D, Karthikeyan P, Ramakrishna S, Davenport M, Dhawan A, dkk. King's Variceal Prediction Score : A novel noninvasive marker of portal hypertension in pediatric chronic liver disease. J Pediatr Gastroenterol Nutr 2017;64:518-23.

11. Megremis SD, Vlachonikolis IG, Tsilimigaki AM. Radiology spleen length in childhood with US : Normal values based on age, sex, and somatometric parameters. Pediatr Imaging 2004;231:129-34. 
Lampiran 1. Pengukuran metode noninvasif dan nilai cut-off $f^{7,9,10}$

\begin{tabular}{|c|c|c|c|c|}
\hline Alat uji & Rumus & $\begin{array}{l}\text { Nilai } \text { cut-off varises } \\
\text { esofagus signifikan }\end{array}$ & $\begin{array}{l}\text { Nilai pada } \\
\text { pasien }\end{array}$ & $\begin{array}{l}\text { Interpretasi } \\
\text { Perlu EGD }\end{array}$ \\
\hline $\begin{array}{l}\text { Clinical prediction } \\
\text { rule }(\mathrm{CPR})\end{array}$ & $\begin{array}{l}\left(\left(0,75 \times \text { jumlah trombosit }\left[\mathrm{x} 10^{3} / \mu \mathrm{L}\right]\right) /(\text { spleen size } z\right. \\
\text { score }+5))+(2,5 \mathrm{x} \text { albumin }[\mathrm{g} / \mathrm{dL}])\end{array}$ & $<114$ & 23,3 & Ya \\
\hline $\begin{array}{l}\text { AST/platelet ratio } \\
\text { index (APRI), } \\
\text { indeks rasio AST } \\
\text { (SGOT)-trombosit }\end{array}$ & $\begin{array}{l}{[\text { AST/batas atas normal }] / \text { jumlah trombosit }\left(\left[10^{3} /\right.\right.} \\
\mu \mathrm{L}] \times 100)\end{array}$ & $>1,4$ & 0,441 & Tidak \\
\hline $\begin{array}{l}\text { Rasio trombosit- } \\
\text { panjang limpa }\end{array}$ & $\begin{array}{l}\text { Jumlah trombosit / panjang limpa (dalam } \mathrm{cm} \text { atau } z \\
\text { score atau equivalent adult spleen size/EASS) }\end{array}$ & $\begin{array}{c}<1(\text { dalam cm }) \\
<25(\text { dalam } z \text { score }) \\
>447,3 \text { (EASS })\end{array}$ & $\begin{array}{c}23,96 \\
42 \\
13.096\end{array}$ & $\begin{array}{c}\text { Tidak } \\
\text { Tidak } \\
\text { Ya }\end{array}$ \\
\hline $\begin{array}{l}\text { Varices prediction } \\
\text { rule (VPR) }\end{array}$ & $\begin{array}{l}\text { [albumin }(\mathrm{g} / \mathrm{dL}) \mathrm{x} \text { jumlah trombosit }\left(\mathrm{x} 10^{3 /}\right. \\
\mu \mathrm{L})] / 1000)\end{array}$ & $<3,63$ & 0,6116 & Ya \\
\hline Risk score & $14,2-7,1 \times\left[\log\right.$ jumlah trombosit $\left.\left(\mathrm{x} 10^{3} / \mu \mathrm{L}\right)\right]$ & $>-1,2$ & $-3,1$ & Tidak \\
\hline \multirow{2}{*}{$\begin{array}{l}\text { King's variceal } \\
\text { prediction score } \\
\text { (KVaPS) }\end{array}$} & $\begin{array}{l}(30 \mathrm{x} \text { albumin }[\mathrm{g} / \mathrm{dL}])-(2 \mathrm{x} \text { equivalent adult spleen } \\
\text { size }[\mathrm{cm}])\end{array}$ & $<76$ & 23,56 & Ya \\
\hline & $\begin{array}{l}\text { Equivalent adult spleen size (EASS) dihitung dengan } \\
\text { rumus berikut. } \\
\text { Laki-laki }=11,29+(1,49 \times \text { z score }) \\
\text { Perempuan }=9,91+(1,27 \times \text { z score }) \\
z \text { score dihitung dari normogram Megremis }{ }^{11}\end{array}$ & & & \\
\hline
\end{tabular}

Keterangan: satuan diubah sesuai dengan satuan yang lazim dipakai di Indonesia. Data pemeriksaan penunjang dapat digunakan dalam kurun waktu 3 bulan terakhir. 